\title{
EVOLUÇÃO HISTÓRICA DA EDUCAÇÃO E DA ESCOLA NO BRASIL
}

BRASIL HISTORICAL EVOLUTION OF EDUCATION AND SCHOOL IN BRAZIL

\section{Débora Rita Kujawa', Amilton Rodrigo de Quadros Martins², Naiana Dapieve Patias ${ }^{3}$}

RECEBIDO EM:01/04/2019 | ACEITO EM: 28/09/2020

DOI: $10.5902 / 2317175837574$

\section{RESUMO}

As discussões acerca da educação e da escola e suas práticas pedagógicas são objetivos de investigações há muitos anos. O processo de escolarização da população brasileira adquiriu vários contornos e significados ao longo da história, resultando em políticas educacionais diversas. Compreende-se que a realidade atual da educação está com suas raízes históricas ativas. Nesse sentido, o presente trabalho teve o intuito de fazer uma breve análise da evolução histórica da educação e da escola, do nascimento da educação formal enquanto prática pedagógica aos dias atuais da educação no Brasil. Para tanto, foram utilizados livros, capítulos de livros e artigos que versavam sobre o tema. Após uma análise crítica dos estudos, a discussão foi dividida nos seguintes tópicos: i) Um pouco sobre a história da educação e da escola; ii) A escola nos dias atuais: Algo mudou? Os resultados sugerem que houve avanços no que diz respeito à educação de maneira geral. No entanto, a escola necessita reinventar-se diante da heterogeneidade de seus alunos e das mudanças sociais atuais. O intuito deste artigo não foi esgotar o tema, mas produzir uma reflexão crítica sobre educação, escola e práticas pedagógicas.

Palavras-chave: História; Educação; Aprendizagem; Escola.

1 Psicóloga, Mestre em Psicologia (IMED).

2 Doutor em Educação Universidade Passo Fundo, docente na IMED.

3 Psicóloga, Doutora em Psicologia pela Universidade Federal do Rio Grande do Sul. Docente do Departamento de Psicologia da Universidade Federal de Santa Maria. 


\section{ABSTRACT}

Discussions about education and the school and its pedagogical practices have been objectives of research for many years. The brazilian population schooling process acquired several contours and meanings throughout history, resulting in several educational policies. It is understood that the present education reality is connected with its historical roots. Therefore, the present work aimed to carry out an analysis of the historical evolution of the development of education and its emergence from the school to the present day. For this, we used books, book chapters and papers that dealt with the topic. After a critical analysis of the studies, the discussion was divided into the following topics: (a) A brief history of education and the school; (b) The school nowadays: Has something changed? The results suggest that there have been advances with regard to the education in a general manner. However, the school needs to reinvent itself in the face of the heterogeneity of its students and current social changes. The intention of this article was not to exhaust the theme, but to produce a critical reflection on education, school and pedagogical practices.

Keywords: History; Education; Learning; School.

\section{Introdução}

No que diz respeito à história da educação e da escola no país, da Colônia ao Império e, por fim, a república, evidencia-se que o projeto de escolarização da população adquiriu diferentes contornos e significados ao longo da história, sendo resultado de políticas educacionais diversas. Mudanças econômicas, sociais e transformações de ordem política impactaram diretamente no processo de escolarização, impondo à escola papéis diferenciados (GOUVÊA, 2007).

A escola é o primeiro ambiente social apresentado à criança após a experiência familiar. Nesse sentido, a escola desempenha um papel muito importante uma vez que, no decorrer da infância e adolescência, desenvolve-se o processo de interação sujeito-sociedade. Se a escola promover diariamente, em seu ambiente, mecanismos propositivos como o diálogo e participação, possibilitará que as relações sociais construídas dentro deste contexto se tornem a base de apoio para o desenvolvimento psicossocial e humano das crianças (VIRÃES, 2013).

No entanto, evidencia-se que a educação escolar vive um profundo paradoxo, uma vez que possui a missão de educar todos os indivíduos, mas, por outro lado, nem sempre concebe as diferenças individuais, sociais e culturais de seus educandos. Parece haver uma dissonância entre o discurso teórico e a prática cotidiana atrelados à própria identidade da instituição escolar, subordinados a uma extensa e sólida tradição normatizante e conservadora, com pouco ou nenhum espaço para a singularidade e a diversidade (CUNHA; DAZZANI, 2016).

A escola, como hoje se conhece, nem sempre possuiu a mesma função. Por isso, a importância de realizar uma análise histórica sobre seu surgimento e evolução serve para compreender de maneira mais aprofundada seus impasses que, de certa forma, apresentam resquícios na atualidade e acabam por interferir na educação dos sujeitos. Saviani (2008) afirma que o conhecimento histórico surge como uma necessidade vital de todo ser humano. Considerando que a realidade humana de cada sujeito se constitui por meio da relação com 
o outro e se desenvolve com o tempo, a memória representa-se como uma essência humana e conquista a sua máxima expressão quando se apresenta como memória histórica. De fato, é por meio da história que os homens se constroem, conhecem e chegam à plena consciência do que são no presente e o que podem vir a ser no futuro. Ou seja, a realidade atual não atua no vácuo, ela está vinculada às raízes históricas intensas, as quais devem ser difundidas e afrontadas para uma melhor compreensão do presente e para além disso, para uma efetiva transformação do futuro (CUNHA; DAZZANI, 2016).

Desta forma, este trabalho pretende fazer uma breve análise da evolução histórica da educação e da escola, do nascimento da educação formal enquanto prática pedagógica aos dias atuais da educação no Brasil.

\section{Um pouco sobre a história da educação e da escola}

A escola, como hoje se conhece, nem sempre possuiu o mesmo status. $\mathrm{Na}$ Europa, até meados do século XIX, a escola era uma instituição para poucos, já que a minoria tinha condições de pagar para frequentá-la e obter os certificados. Desta forma, as escolas eram exclusivamente frequentadas por classes sociais privilegiadas, aqueles que garantiam o sustento familiar mantendo seus filhos afastados do trabalho (BARROSO FILHO, 2000).

Em contexto nacional, o processo de escolarização seguiu passos não muito distintos. Até o século $\mathrm{XIX}, \mathrm{O}$ analfabetismo era muito comum em uma sociedade quase que totalmente "desescolarizada". As elites escravistas brasileiras, na Colônia e no Império, conviviam com multidões de analfabetos sem nenhuma atitude de desprezo sendo que o analfabetismo não era objeto de escândalo, pois era comum até entre as elites portuguesas (BARROSO FILHO, 2000). Já na época da Colônia (1500-1822), a condição da educação consistia no conteúdo cultural repassado pelos padres jesuítas. $O$ ensino que eles prestavam era totalmente impróprio à realidade de vida da Colônia, pois era destinado à transmissão de cultura geral básica, sem pretensão de qualificar para o trabalho. Desta forma, o ensino não contribuía para mudanças das estruturas de vida social e econômica. Por outro lado, a educação não representava uma preocupação, pois as atividades de produção não exigiam preparo, nem para a administração nem para mão de obra. Assim, a utilidade do ensino era somente para alguns "espíritos ociosos" que não eram destinados a administração da unidade produtiva e que podiam se dar o capricho de se cultivarem (ROMANELLI, 1978).

Dadas algumas circunstâncias, como a decadência econômica, a queda da mineração, o atraso cultural do Reino Português e o fanatismo religioso, surgiu um descontentamento em relação aos Jesuítas, e por consequência a exclusão desses. Com isso, surgiram também dificuldades para a educação, pois dada a exclusão dos Jesuítas, passaram-se 13 anos até a substituição de educadores. Ainda, leigos foram introduzidos no ensino e o Estado assumiu as atribuições da educação, embora a condição da educação não tenha mudado 
em suas bases, o ensino ainda era destinado às classes dominantes, o que perdurou até a época imperial (ROMANELLI, 1978).

No período imperial (1822-1889) o Estado era responsável pelas atribuições da educação, porém, o significado da educação pública não tinha sentido de educação popular, ainda não era vista como um meio necessário para disseminação dos conhecimentos essenciais para a formação de cidadania e constituição da nacionalidade (MIGUEL, 1999). Os filhos dos pobres negros não tinham a opção de educação, para eles o dever era se transformar em cidadãos úteis e produtivos nas lavouras, enquanto os filhos de elites eram ensinados por professores particulares (VIVEIROS, 2006). Neste período, a educação objetivava a transmissão de valores morais, de conhecimentos básicos de língua e aritmética, centrados no ler, escrever e fazer contas. Considerava-se que esses conhecimentos eram fundamentais para a garantia da moralização e instrução às classes pobres, as quais eram tomadas como potencial fonte de agitação social, ou incapazes de tornarem-se sujeitos civilizados (GOUVÊA, 2007).

Importante referir que no final do período imperial registraram-se algumas manifestações isoladas de revolta diante do analfabetismo que reinava entre os pobres, os trabalhadores manuais, os "órfãos da sorte" e os desvalidos. Mas ainda no período republicano, após o período imperial, ao final do século XIX e início do século XX, a escolarização dos pobres era vista com temor, pois colocava em risco a "ordem natural" da sociedade (BARROSO FILHO, 2000).

O fim do Império e início da República (1889-1930) foi marcado pela abolição da escravatura e logo após a implantação do capitalismo industrial (ROMANELLI, 1978). Esse processo desencadeou uma mudança estrutural no modelo de trabalho, pois fez a troca do trabalho escravo para o assalariado no campo e mudou o quadro da economia no Brasil. Além disso, ocorreu a imigração em massa de povos europeus, com isso, parte da população negra, que antes era escravizada, passou a morar nos centros urbanos. A partir destas mudanças houve um grande aumento na industrialização brasileira, surgindo a necessidade de promover a educação profissional para as classes menos favorecidas economicamente (TENÓRIO, 2009).

Esse período de revolução industrial é demarcado por um novo contrato social em que a escola se apresenta como instituição obrigatória para garantia da ordem e do progresso. O Estado passa a ser, a partir deste momento, o disciplinador social vigiador de conduta. Naturalizava-se a disciplinarização dos saberes, para os sujeitos acreditarem que esta era a única maneira de vida possível para se viver bem. As salas de aulas eram organizadas em filas para assegurar o controle e o trabalho de cada aluno, assim era possível classificar e individualizar as diferenças de cada um (FOUCAULT, 1999).

A escola surge como adestradora social, sendo incumbida de mediar a aprendizagem de padrões culturais e sociais exigidas pela necessidade de conviver em um mundo popular cada vez mais complexo. O papel da escola 
era civilizar, controlar e doutrinar, uma vez que o cenário era marcado pelo estabelecimento de um novo modelo de Estado. O interesse da nova ordem política era a educação de todos, assim, era necessária a viabilização da educação a todos e ao mesmo tempo dentro das condições possíveis, para isso a sala de aula mostrou-se como uma solução eficaz. A organização da escola era centrada no conhecimento em disciplinas, ministradas por professores para determinado número de alunos (BOUFLEUER; PRESTES, 2013).

No período industrial houve vários problemas estruturais na educação brasileira, assim como também ocorreu um avanço na educação profissional, o qual produziu uma nova configuração. A escola tinha uma finalidade clara que era a formação de operários e soldados, obedientes e focados, através de ensino prático e conhecimentos técnicos necessários, de acordo com o interesse da Federação em que a escola estivesse funcionando (TENÓRIO, 2009). Contudo, ainda nessa época, desencadeou-se um debate acerca dos modos de aprender, envolvendo as circunstâncias específicas dos alunos pois se percebeu que havia uma distância entre o conhecimento ministrado pelo professor e a sua efetiva aprendizagem por parte dos alunos. Neste momento, a pedagogia entrou em cena, mostrando que educar não era apenas transmitir conteúdos, educar implica também em formas de mediação que impõe novas competências para além daquelas que se referem ao saber das disciplinas (BOUFLEUER; PRESTES, 2013).

Passado esse período, em 1930, na "Era Vargas", instalou-se um Governo Provisório, sob Presidência de Getúlio Vargas, o qual cria por meio do decreto n 19.402, de 14/11/30, o Ministério dos Negócios da Educação e Saúde Pública. Esse Ministério tinha como dever o estudo e encaminhamento de todos os assuntos referentes ao ensino, à saúde e à assistência hospitalar. $O$ novo Ministério, sob o comando do Ministro Sr. Francisco Campos, fundado com poderes amplos e com controle sobre o setor educacional, realiza como uma das primeiras ações a reforma conhecida como "Reforma Francisco Campos", a qual se firma com o estabelecimento de uma série de decretos. À essa reforma educacional é creditado o mérito, pois pela primeira vez colocou-se em prática, no sistema escolar brasileiro, uma estrutura orgânica ao ensino secundário, comercial e superior (ROMANELLI, 1978).

Após, entre os anos de 1931 a 1961, foi regulamentado em âmbito nacional as escolas superiores, secundárias e primárias, as quais foram incorporando-se em um crescente ideário pedagógico renovador. Por fim, entre os períodos de 1961 e 1996, ocorreu a unificação da regulamentação da educação nacional abrangendo as redes públicas e privadas, que foram sendo moldadas de acordo com a concepção produtivista de escola. Neste período foi instituída a Constituição Federal Brasileira de 1988 (Brasil, 1988) e a Lei de Diretrizes e Bases da Educação Nacional - LDB, Lei n. 9.394 (Brasil, 1996), as quais reafirmam o Ensino Fundamental obrigatório e gratuito e, ainda, asseguram o direito de ensino aos jovens e adultos que não tiveram acesso, 
assim como a progressiva universalização do Ensino Médio gratuito (SAVIANI, 2005).

Na prática, observou-se que no período do governo de Fernando Collor de Mello (1990-1992) solidificado com o governo de Fernando Henrique Cardoso (1995-1998/1999-2002), houve uma forte invasão da lógica neoliberal, em que os ideais estavam voltados aos interesses capitalistas, impactando diretamente na educação. Neste período, muitas escolas brasileiras introduziram um modelo mercadológico, investindo em uma organização escolar gerencial onde a eficiência e produtividade era o foco, ou seja, os interesses educacionais eram regidos de acordo com os interesses do mercado, priorizando os investimentos que gerassem custo-benefício para área da educação (FLACH, 2012). Esse modelo foi perdendo forças após a eleição do presidente Luiz Inácio Lula da Silva em 2003.

Aliada a essa trajetória histórica, existiram movimentos teóricos, os quais não foram objetivo deste estudo, mas cabe ressaltar brevemente, para compreender-se como se chegou aos objetivos da educação e dever da escola atual. Por exemplo, no século XVIII um movimento popular iniciou uma oposição ao movimento burguês, assim, duas forças opostas surgem no século XIX, o marxismo e o positivismo. A educação positivista, teve como maior representante Augusto Conte (1798-1857) e Émile Durkheim, (1858-1917), um dos seus principais expoentes, o qual concebia a educação como reflexo da sociedade, sendo assim, considerava a educação um fator social e o homem um ser social e, portanto, seu dever é formar o cidadão que fará parte da sociedade, e nisso se inclui o aprendizado das normas sociais vigentes no contexto. Ou seja, a educação positivista visava a racionalidade, a libertação social e política passava pelo desenvolvimento da ciência e da tecnologia, sob o controle da elite. O movimento marxista foi representado por Karl Marx (1818-1883), mas a educação fundamentada nas ideias marxistas possui vários representantes, entre eles Anton Makerenko e Lev Vygotsky. A concepção de educação marxista preconizava a educação para todos, que esta fosse pública e gratuita e que ainda deveria formar homens integralmente desenvolvidos (GADOTTI, 2004).

Além desses dois movimentos, surge no século $X X$ como renovação da escola burguesa o movimento da Escola Nova. O objetivo da educação escolar neste movimento era incentivar a mudança social e ao mesmo tempo transformar a sociedade que estava em mudança, ou seja, transformar a educação em um processo ativo valorizando a ação da criança. Esse movimento repercutiu sobre o mundo todo diferentes métodos ou técnicas de ensino, em especial, sobre o pensamento pedagógico brasileiro, que começou a ter autonomia após o desenvolvimento das teorias da Escola Nova (GADOTTI, 2004). 


\section{A escola nos dias atuais: Algo mudou?}

A partir desse regaste histórico sobre a educação e constituição da escola, observam-se dois aspectos relevantes e que, em algum momento, ainda estão presentes na educação e na escola atual. O primeiro refere-se à exclusão, evidenciada com grande ênfase, na época colonial e imperial, nas quais o acesso à educação era somente aos filhos de elites. $O$ segundo aspecto refere-se à seleção/classificação, caracterizada fortemente no período republicano, com a industrialização, na qual o interesse da educação era formar pessoas para o mercado de trabalho. Para isso, selecionava-se os que se destacavam como melhores, na concepção da escola. Nesse sentido, acrescenta-se as afirmações de Pan e Zugman (2015) os quais afirmam que, por muitos anos, uma das funções principais da escola era selecionar os alunos considerados melhores para o mercado de trabalho. Assim, a escola era quem determinava os que tinham condições de dar continuidade aos estudos ou buscar um trabalho desde cedo.

A exclusão e a seleção são dois temas ainda presentes nas escolas atuais e que produz grandes discussões. Evidencia-se a presença da seleção no contexto escolar atual quando se observa o sistema de avaliação da aprendizagem. 0 sistema de avaliação de desempenho em muitas escolas é ainda baseado na atribuição de nota a partir de uma prova ou exame, ou seja, baseado no ato de examinar, caracterizado pela classificação dos alunos melhores e os alunos piores. Um estudo cujo objetivo era discutir os efeitos aversivos das práticas tradicionais de avaliação da aprendizagem escolar com alunos, evidenciou diversos efeitos causados por estas, tais como: medo e ansiedade, sentimento de incapacidade, perda de motivação para estudar, frustração e exclusão, deterioração da relação sujeito-objeto, entre outros. Identificou-se que as práticas de avaliação empregadas cumpriam o papel de classificar o aluno em algum nível e, por consequência, estigmatizá-los (LEITE; KAGER, 2009).

A exclusão é ainda muito presente no dia-a-dia das escolas brasileiras. Uma pesquisa, cujo objetivo foi analisar o sentido da escola para adolescentes em situação de vulnerabilidade social, revela dados em que os estudantes identificam falhas da escola na garantia do direito a uma educação de qualidade. Os alunos afirmam que a dinâmica das aulas é insatisfatória, que alguns profissionais possuem postura inadequada, que eles não possuem oportunidades para se expressarem, para participarem de processos decisórios e, ainda, as disciplinas possuem conteúdos que não condizem com suas realidades (LEITE, ET AL. 2016). Compreende-se que essas situações relatadas pelos alunos são caracterizadas como um tipo de exclusão, uma vez que os alunos não possuem vez para se expressarem, a realidade e as vivências pessoais não são consideradas, ou seja, ignora-se, exclui-se a subjetividade do aluno. Nesse sentido observa-se que o sistema educacional possui duas formas de exclusão, sendo a exclusão da escola e a exclusão na escola. A primeira, 
exclusão da escola, faz referência ao não acesso à escola e à evasão escolar e a segunda, exclusão na escola, refere-se a uma exclusão praticada dentro do sistema educacional, por meio do mecanismo da reprovação (FERRARO, 1999).

Uma pesquisa com o intuito de caracterizar o trabalho desenvolvido nas classes de aceleração de aprendizagem sobre os efeitos produzidos em adolescentes com histórico de fracasso escolar, em seus pais e nos professores, evidenciou que houve um aumento na autoestima e no desempenho escolar dos alunos. Os alunos que participaram da pesquisa tinham um histórico de reprovação de dois ou mais anos de ensino e, segundo uma professora, eram alunos que já não tinham mais uma "identidade de estudante" (PEZZI; MARIN, 2016). Essa fala da professora deixa clara a exclusão da escola, definida por Ferraro (1999).

O tema da exclusão indica que as relações da escola e da sociedade se transformaram e que o ambiente escolar perdeu sua virtude, uma vez que a escola é um agente exclusivo. Essa afirmação é posta visto que a escola transforma a experiência dos alunos, o que, frequentemente, produz uma crise de sentido nos estudos e, às vezes, até uma crise de legitimidade da instituição escolar. A exclusão é instituída na medida que a escola quer afirmar a igualdade dos indivíduos, mas ao mesmo tempo ela considera a desigualdade de seus desempenhos. Percebe-se que apesar de seus princípios e de suas ideologias, a escola atualmente é mais integrativa, contudo, é também mais exclusiva, o funcionamento do contexto escolar é como um mercado, cujo princípio básico é integrar, mas também excluir (DUBET, 2003).

Com esse cenário, a escola parece ainda se manter ancorada a um modelo de instituição estabelecida no período de revolução industrial no qual os objetivos que compõem o processo de escolarização são: educar em ambientes fechados e na posição de filas, controlar o tempo dos alunos, selecionar os saberes e dar a eles caráter universal, adequando-os às capacidades dos alunos, instituir uma obrigatoriedade escolar de modo que torne os cidadãos tutelados pelo Estado (CORREA, 1997).

Sendo assim, parece que a escola atual deve se reajustar aos novos e diferentes alunos para que possa se construir papéis e valores únicos para uma geração que necessita muito mais da vivência de novas experiências do que compreender papéis ou valores obsoletos para os tempos atuais. A função civilizadora da escola de propiciar modelos culturais e racionalizar sujeitos para gerenciar o mundo parece estar enfraquecendo na contemporaneidade (SCHWERTNER; MUNHOZ, 2017).

Esse enfraquecimento é bastante discutido, trata-se do fenômeno chamado "fracasso escolar". Na medida em que a população pertencente às classes populares teve acesso à escola, esse fenômeno foi tomando força, especialmente nas últimas décadas do século XX. O direito do acesso à escola está garantido pela Constituição Federal de 1988, reafirmado e regulamentado pela LDB 9394/96 e no Estatuto da Criança e do Adolescente (ECA), contudo, 
o fato de estar garantido em lei não significa que efetivamente todos estão tendo acesso, pois ainda se enfrenta um alto índice de evasão e repetência nas escolas públicas brasileiras, e este é um grande desafio a ser superado. Não basta crianças e adolescentes terem a garantia do acesso à escola, é necessário que seja garantido também a sua permanência e o seu progresso (FORGIARINI; SILVA, 2008).

Em uma pesquisa de campo com gestores, professores e funcionários de uma escola pública do Oeste do Paraná, no período de 2007 a 2008, observouse que a responsabilização pelo fracasso escolar foi atribuída a fatores externos à escola, referindo que, frequentemente, a culpa do fracasso é do aluno e da sua família (FORGIARINI; SILVA, 2008). É comum ouvir relatos de professores ou membros da equipe da escola de que o baixo desempenho e desinteresse do aluno é devido à sua família "desestruturada", desinteressada, carente, e ainda, em comunidades de baixa renda, comenta-se sobre famílias violentas. No entanto, essas condições não representam uma "justificativa" para o insucesso escolar da criança. Basta alguns minutos de reflexão para os professores e agentes da escola se darem conta que esse raciocínio preconceituoso só serve para a escola se eximir do problema, visto que este é consequência de uma situação externa à escola (SZYMANSKI, 1997).

Percebe-se que há um conjunto de fatores que assolam a educação escolar, neste texto destacam-se problemas que por vezes a escola se dá conta e quer eximir-se da responsabilidade e, assim, incumbe à família e outros, que por vezes passam despercebidos. A escola não se dá conta de que está fadada a um sistema que exclui pela sua forma de avaliar o desempenho do aluno, pelo seu método pedagógico que ainda é guiado pela transmissão de conteúdo sem muitas vezes condizer com a realidade dos alunos, um sistema que não oportuniza a expressão e vivência de seus educandos.

Para superar os desafios que as escolas do país enfrentam atualmente, o contexto educativo brasileiro, são necessárias inúmeras mudanças, as quais não dependem somente da escola. No entanto, a escola deve cumprir com seus deveres os quais são: levar em consideração o contexto do aluno, pois este refletirá em sua formação, aprender a conviver com as diferenças e as constantes mudanças familiares e, ainda, participar ativamente dessas mudanças, promovendo-as em sua forma de atuação, a fim de saber lidar tanto com a família que tem tempo disponível para uma participação maior quanto àquela em que os pais não têm tempo, isso porque ambas possuem preocupações que são similares (CARVALHO, 2000).

Além disso, faz-se necessário que a escola repense algumas práticas pedagógicas com o intuito de promover a aprendizagem efetiva de todos. Para isso, precisa-se de um sistema escolar que não se preocupe somente com as notas, mas sim com a aprendizagem e construção do conhecimento, de uma escola que possua uma concepção política-pedagógica, que seja autônoma, responsável, que possua clareza política sobre o que tem que ser feito e 
competência técnica para executar os processos (FORGIARINI; SILVA, 2008).

\section{Considerações finais}

A partir da análise história sobre a evolução e desenvolvimento da educação e da escola brasileira, foi possível identificar uma evolução significativa e positiva, no que se refere ao desenvolvimento do processo de educação e os diferentes papéis e objetivos exercidos pela escola nas diferentes épocas, sendo que as mudanças ocorreram de forma gradual. Destacou-se como marco para garantia dos direitos e deveres da educação nos dias atuais a Constituição Federal Brasileira de 1988 e a Lei de Diretrizes e Bases da Educação Nacional - LDB de 1996, estas foram um reflexo de movimentos teóricos que mostraram a necessidade de transformar a educação em um processo ativo em decorrência das mudanças da sociedade, e, portanto, necessitava de homens integralmente desenvolvidos.

Desde então, a escola exerce uma função de auxiliar na formação de padrões coletivos de agir e de conviver, visando a construção e transmissão das tradições culturais, a socialização de novas gerações e formação de sujeitos com identidades pessoais (BOUFLEUER; PRESTES, 2013). Na medida em que se reconhece a escola como responsável pela formação da cultura, é preciso pensar no tipo de cultura que a escola está produzindo e, especialmente, quais são as influências dessa cultura na sociedade e vice-versa, qual a influência que a sociedade produz sobre a cultura da escola. Grande parte das escolas da sociedade atual são apenas instituições que exercem a cultura de formar indivíduos, todavia, esta formação na maioria das vezes não transcende uma atividade mecânica na qual o professor é o possuidor do conhecimento e os alunos, meros reprodutores (VIRÃES, 2013).

Percebe-se que o sistema escolar atual ainda está ancorado a um sistema instituído no início do século passado. A geração atual necessita muito mais da vivência de novas experiências para compreender os papéis e os valores, ou seja, é preciso incluir os alunos no processo de construção e vivência dos valores e não somente na transmissão.

É notável que houve uma mudança significativa no decorrer da evolução histórica da educação escolar, porém, esse sistema enfrenta atualmente alguns impasses os quais giram em torno do "fracasso". O fracasso originase de problemas relacionados ao sistema escolar, sendo questões de gestão pedagógica, método de ensino e aprendizagem, relações com interface família-comunidade etc. Porém, não se pode ignorar que esses problemas também estão relacionados a questões políticas e sociais. Como referido anteriormente, a evolução e garantia dos direitos é fruto de movimentos teórico-sociais.

Nesse sentido, alguns autores descrevem que o fracasso escolar está relacionado diretamente ao fracasso da sociedade, se a escola não vai bem é porque a sociedade não vai bem, ou seja, o fracasso escolar é um fator decorrente 
de uma crise geral. Portanto, para compreender esse fenômeno e a totalidade do processo educacional não se deve ficar no limite do cotidiano escolar, é preciso analisar as relações determinantes deste cotidiano e seus problemas, pois com eles estão sobrepostas todas as questões da sociedade capitalista. Para se compreender as formas de superação, avaliação, encaminhamento e tratamento do fracasso escolar é necessário que se estabeleça uma relação entre a escola e o processo histórico (FACCI ET AL., 2007).

Progressivamente a escola vem perdendo o seu status de mantenedora absoluta do conhecimento, ficando cada vez mais evidente a necessidade de repensar as propostas didáticas que vêm sendo desenvolvidas em sala de aula, para que os alunos nativos deste contexto tecnológico não percam o interesse pelo conhecimento que é produzido na escola e possam, de fato, estarem preparados para usufruir deste contexto tecnológico. É fundamental que se perceba a necessidade de abertura de novas propostas metodológicas as quais

precisaram estar vinculadas a um projeto.

Por fim, cabe frisar que para que isso ocorra é de fundamental importância que a escola seja um ambiente determinado à verdadeira formação, bem como esta deve abranger o domínio do pensamento reflexivo, de modo que motive os indivíduos a buscarem uma sociedade menos injusta e com mais influência sobre os meios de divulgação em massa (RAMOS-DE-OLIVEIRA, 2001).

\section{Referências}

BARROSO FILHO, G. (2000). Universalização da Escola Pública do "Para que?" ao "Quanto?". Revista Contexto \& Educação, 59, 07-20. Retrieved from <https://revistas.unijui.edu.br/index.php/contextoeducacao/article/ viewFile/1229/981>

BOUFLEUER, J. P.\& PRESTES, R. M. (2013). A escola que avalia e que é avaliada: o papel da escola na construção de um mundo humano comum. Revista Educação, 36(2), 240-249. Retrieved from <http:// revistaseletronicas.pucrs.br/ojs/index.php/faced/article/view/12014/945>

BRASIL (1988). Constituição da República Federativa do Brasil. Presidência da República. Brasília, DF.

BRASIL (1990). Estatuto da Criança e do Adolescente, Câmera dos Deputados, Lei no 8.069, de 13 de julho de 1990 - ECA. Brasília, DF.

BRASIL (1996). Lei n 9.394. Estabelece as Diretrizes e Bases da Educação Nacional, de 20 de dezembro de 1996. Presidência da República. Brasília, DF.

CARVALHO, M. E. P. Relações entre família e escola e suas implicações de gênero. Cadernos de Pesquisa, 110, 144155. Retrieved from <http://www.scielo.br/pdf/cp/n110/n110a06.pdf>

CORREA, G. C. (1997). Permanência e mudança: desejo de cientificidade nas relações entre Ciência e Escola. Revista Perspectiva, 15(27), 121-133. Retrieved from <https://periodicos.ufsc.br/index.php/perspectiva/article/ view/10568/10101>

CUNHA, E. O., \& DAZZANI, M. V. M. (2016). Da repulsão da escola à diferença: historicizando raízes, perspectivando saída. In: M. V. M. Dazzani \& V. L. T. de Souza (Orgs), Psicologia Escolar Crítica: Teoria e Prática nos contextos educacionais. (pp. 57-73). Campinas: Alínea.

DUBET, F. (2003). A escola e a exclusão. Revista Cadernos de Pesquisa, 119, 29-45. Retrieved from <http://www. scielo.br/pdf/cp/n119/n119a02.pdf > 
EVOLUÇÃO HISTÓRICA DA EDUCAÇÃO E DA ESCOLA NO BRASIL

FACCI, M. G. D., TESSARO, N. S., LEAL, Z. F. DE. R. G., SILVA, V. G. DA., \& ROMA, C. G. (2007). Psicologia histórico-cultural e avaliação psicológica: o processo ensino aprendizagem em questão. Psicologia Escolar e Educacional, 11(2), 323-338. Retrieved from<http://pepsic.bvsalud.org/scielo.php?script=sci_ arttext\&pid=S1413-85572007000200011\&lng=pt\&nrm=iso>

FERRARO, A. R. (1999). Diagnóstico da escolaridade no Brasil. Revista Brasileira de Educação, 12, 22-47. Retrieved from <http://anped.tempsite.ws/novo_portal/rbe/rbedigital/RBDE12/RBDE12_04_ALCEU_RAVANELLO_ FERRARO.pdf>

FLACH, S. F. (2012). Contribuições para o debate sobre a qualidade social da educação na realidade brasileira. Revista Contexto \& Educação,87, p. 4-25. Retrieved from<https://www.revistas.unijui.edu.br/index.php/ contextoeducacao/article/view/191/307>

FORGIARINI, S. A. B., \& SILVA, J. C. (2008). Fracasso escolar no contexto da escola pública: entre mitos e realidades. Secretaria de Educação do Paraná. Retrieved from <http://www.diaadiaeducacao.pr.gov.br/portals/pde/ arquivos/369-4.pdf>

FOUCAULT, M. (1999). Vigiar e Punir: a história da violência nas prisões. Petrópolis: Vozes.

GADOTTI, M. (2004). História da Ideias pedagógicas. São Paulo, SP: Ática.

GOUVÊA, M. C. S. (2007). A escolarização da criança brasileira no século XIX: Apontamentos para uma reescrita. Revista Educação em Questão, 28(14), 121-146. Retrieved from <https://periodicos.ufrn.br/ educacaoemquestao/article/view/4467/3658>

LEITE, F. M., PESSOA, M. C. B., SANTOS, D. P. DOS., ROCHA, G. F., \& ALBERTO, M. de. F. P. (2016). O sentido da escola: Concepções de estudantes adolescentes. Psicologia Escolar e Educacional, 20(2), 339-348. Retrieved from <http://www.scielo.br/scielo.php?script=sci_arttext\&pid=S1413-85572016000200339\&lng=en\&nrm=iso>

LEITE, S. A. S., \& KAGER, S. (2009). Efeitos aversivos das práticas de avaliação da aprendizagem escolar. Ensaio: Avaliação e Políticas Públicas em Educação 17(62), 109-134. Retrieved from <http://www.scielo.br/ scielo.php?script=sci_arttext\&pid=S0104-40362009000100006\&lng=en\&nrm=iso>

MIGUEL, M. E. B. (1999). O significado da educação pública no Império (Paraná província). In: L. M. Faria Filho (Org.), Pesquisa em história da educação: Perspectivas de análise, objetos e fontes (pp. 87-94). Belo Horizonte: HG Edições.

PAN, M. A. G. S., \& ZUGMAN, M. J. (2015). Psicologia e políticas inclusivas na Educação: contribuições de uma leitura Bakhtiniana. Revista Estudos e Pesquisa em Psicologia, 15(1), 135-154. Retrieved from <http://pepsic. bvsalud.org/scielo.php?script=sci_arttext\&pid=S1808-42812015000100009\&lng=pt\&nrm=iso>

PEZZI, F. A. S., \& MARIN, A. H. (2016). "Seguindo em frente!": O fracasso escolar e as classes de aceleração. Psicologia Escolar e Educacional, 20(2), 219-227. Retrieved from <http://www.scielo.br/ scielo.php?script=sci_arttext\&pid=\$1413-85572016000200219\&lng=en\&nrm=iso>

RACY, P. M. P. de B. (2001). Psicologia da educação: origem, contribuições, princípios e desdobramento. Curitiba: Ibpex.

RAMOS-DE-OLIVEIRA, N. (2001). Do ato de ensinar numa sociedade administrada. Cadernos CEDES, 21(54), $19-27$. Retrieved from <http://www.scielo.br/scielo.php?script=sci_arttext\&pid=S0101-32622001000200003\&lng $=e n \& n r m=i s o>$

ROMANELLI, O. de O. (1978). História da Educação no Brasil. Petrópolis, Rio de Janeiro: Vozes Ltda.

SAVIANI, D. (2005). História da escola pública no Brasil: questões para pesquisa. In: J. C. Lombardi, D.Saviani \& M. I. Nascimento (Orgs.), A escola pública no Brasil: história e historiografia. (pp. 1029). Campinas: Autores Associados.

SAVIANI, D. (2008). História da história da educação no brasil: um balanço prévio e necessário. Revista Científica EccoS, 10, 147-167. Retrieved from <http://www.redalyc.org/articulo.oa?id=71509907>

SCHWERTNER, S. F., \& MUNHOZ, A. V. (2017). Imagens da escola e suas funções na contemporaneidade: o discurso de estudantes concluintes do ensino médio. Revista Imagens da Educação, 7(1), 58-69. Retrieved from <http://periodicos.uem.br/ojs/index.php/ImagensEduc/article/view/30285/pdf>

SZYMANSKI, H. (1997). Encontros e desencontros na relação família-escola. Idéias, 25, 213-225. Retrieved from 
<http://www.necfebf.uerj.br/boletins/boletim012011index_arquivos/HeloisaSzymanski.pdf>

TENÓRIO, N. C. (2009). O Ensino no Brasil: da República Velha à Reforma Francisco Campos - uma releitura. Revista Espaço Acadêmico, 92, 1-7. Retrieved from <https://www.passeidireto.com/arquivo/5038079/reformafrancisco-campos-para-os-alunos>

VIRÃES, M. B. A. R. de A. (2013). O Papel da Escola na Educação de Valores. (Dissertação, Universidade Lusófona de Humanidades e Tecnologias Instituto de Educação, Lisboa. Retrieved from <http://recil.grupolusofona. pt/bitstream/handle/10437/4831/Maria_Betania_Viraes_Disserta\%C3\%A7\%C3\%A3o.pdf?sequence=1>

VIVEIROS, K. F. M. de (2006). A criança negra no Maranhão: uma leitura a partir da infância afro-descendente no Brasil. In: Congresso Brasileiro de História da Educação, 6. Goiânia: Sociedade Brasileira de História da Educação. Retrieved from <http://www.sbhe.org.br/novo/congressos/cbhe4/individuais-coautorais/eixo04/ Kilza\%20Fernanda\%20Moreira\%20de\%20Viveiros\%20-\%20Texto.pdf> 